
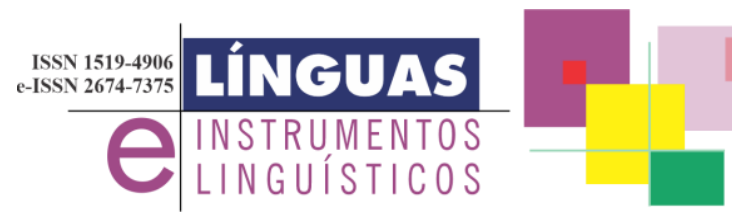

DOI: $10.20396 /$ lil.v24i47.8666688

\title{
De onde vem a língua falada nas canções?
}

\section{Where does the language spoken in songs come from?}

\author{
Pedro de Souza* \\ $\mathrm{UFSC} / \mathrm{CNPq}$
}

Resumo: Este artigo propõe elementos para investigar como a voz na canção popular brasileira pode trazer uma modalidade de arquivo da história do português falado. O texto parte do conceito de variantes da língua oral, em diferentes tempos e lugares, que só são acessíveis na canção popular que circula de uma região para outra. O objetivo é contribuir com uma abordagem inovada para a história dos diferentes momentos da língua portuguesa falada no Brasil. Metodologicamente, tomamos a canção popular brasileira como referencial da língua em contínuo movimento. Como resultado, espera-se avançar para uma pesquisa que reúna um produtivo arquivo da língua atestando seus diferentes períodos registrados na voz articulada na linguagem das canções.

Palavras-chave: Voz, Enunciação, Canção, Variedade linguística.

Abstract: This article proposes elements to investigate how the voice in Brazilian popular song can bring an archival modality of the history of spoken Portuguese. The text starts from the concept of variants of the oral language, in different times and places, which are only accessible in popular songs that circulate from one region to another. The objective is to contribute with an innovative approach to the history of the different moments of the Portuguese language spoken in Brazil. Methodologically, we take Brazilian popular song as a reference for 
the language in continuous movement. As a result, it is expected to advance towards a research that brings together a productive archive of the language attesting to its different periods recorded in the articulated voice in the language of songs.

Keywords: Voice, Enunciation, Song, Linguistic variety.

\section{Introdução}

A música popular brasileira atravessa as práticas culturais em suas muitas modalidades: a festa, a religião, o trabalho, a política. Neste âmbito, é possível investigar, nos arquivos da canção brasileira, registros da memória da língua falada. Trata-se de descrever historicamente não apenas o estado da sistematicidade formal de uma língua ao longo de sua história, mas como os falantes se apropriam dela em seu cotidiano comunitário. Tal é a motivação que conduz a percorrer a história das práticas linguísticas sonoramente assinaladas na canção.

O pressuposto, neste artigo, é o de que o cancioneiro popular é ponto de origem de certos modos de falar ainda pouco atestáveis na linguagem ordinária do português falado. Tradicionalmente a literatura tem sido o tipo de cultura onde mais se investigou a presença transcrita das mais variadas maneiras de falar a língua portuguesa, em diversos contextos sociais - rural ou urbano. Oportuno lembrar que nos escritos de Guimarães Rosa seus personagens existem sobretudo a partir de seus singulares modos de falar. Riobaldo, de Grande sertões e veredas, só se torna audível por seu inventivo modo de falar que o narrador transcreve. Sobre a língua falada em seus contos e romances, Rosa disse uma vez:

(...) eu quero aproveitar tudo o que há de bom na língua portuguesa, seja do Brasil, seja de Portugal, de Angola ou Moçambique, e até de outras línguas: pela mesma razão, recorro tanto às esferas populares como às eruditas, tanto à cidade como ao campo. (...) Tenho montes de cadernos com relações de palavras, de expressões. Acompanhei muitas boiadas, a cavalo, e levei 
sempre um caderninho e um lápis preso ao bolso da camisa, para anotar tudo o que de bom fosse ouvido - até o cantar de pássaros. Talvez o meu trabalho seja um pouco arbitrário, mas se pegar, pegou. A verdade é que a tarefa que me impus não pode ser só realizada por mim. (GUIMARÃES ROSA, $1966^{1}$ ).

O que recorto, na citação deste depoimento, é a atitude do escritor com relação à língua que ele ouve ao longo de suas viagens. Por certo, as palavras e expressões que anota vão compor uma narrativa literária que deverá obedecer à linguagem própria da escrita do romance. Mas se Guimarães Rosa age de maneira respeitosa em relação à língua que lhe vem circunstancialmente aos ouvidos é porque está linguisticamente atento a homens falando, e nunca à língua dos manuais da gramática.

Daí é possível pressupor uma minuciosa e atenta escuta da língua falada a partir da qual o escritor tece a composição de seus personagens. Importante salientar que o ouvido atento do escritor guarda e anota, na memoria auditiva, o ritmo, a prosódia, a musicalidade da fala que vem pela voz. Portanto, a língua falada que compõe, com tal unicidade as personagens de um conto, uma novela ou um romance é ressonância de uma linguagem ordinária, já falada antes da história que conta o escritor.

No campo da Sociolinguística, Dino Pretti muito chamou atenção para o uso da literatura como espaço em que se pode estudar as variedades de uma língua. Contudo o autor adverte que não é possível estudar a língua oral por meio de documentos literários: “(...) será sempre uma incógnita para escritores, críticos e leitores julgar o mérito das vozes que intervêm na prosa literária, criando personagens e narradores naturais, isto é, integrados na "ilusão da realidade", um dos índices da literatura" (PRETTI, 1997, p. 43).

A questão de Pretti é como, relacionando a língua falada e a linguagem dos personagens literários, descrever uma série de traços constitutivos de uma comunidade e os falantes envolvidos em certo ato de fala, citado na forma de discurso direto em primeira pessoa na escrita de uma narrativa. Através de alguns exemplos de escritores brasileiras, Pretti expõe as dificuldades de chegar a uma descrição sociolinguística precisa baseando-se apenas na forma escrita da fala reconstituída. 
De uma maneira geral, pode -se dizer que, na linguagem literária, em particular no diálogo, apesar de todas as tentativas dos escritores, de se aproximarem da língua oral, existe um limite bem demarcado entre a transcrição de um texto falado e a linguagem literária imaginada pelo escritor para fazer corresponder à realidade, pelo menos na prosa de costumes. E esse limite é determinado pelas estruturas de expectativa (negrito do autor) do leitor, pelo seu grau de aceitação das formas orais na linguagem escrita, ou seja, pelo que ele "espera" encontrar num texto literário, desde que, a priori, ele o admita como tal (PRETI, 1997, p. 55).

Do questionamento levantado por Dino Pretti acerca da relação entre a fala dentro e fora do texto literário, quero desenvolver elementos de análise tratando da relação entre a língua falada que se realiza fora e dentro da canção popular brasileira. Meu ponto de partida é a suposição de que o traço prosódico que gera a musicalidade da fala pode ser o mesmo que gera a música da canção. Neste sentido, a distância entre a língua falada e a fala composta em letra e melodia na canção atinge o grau zero do que Emile Benveniste definiria como enunciação, ou o "(...) colocar em funcionamento a língua por um ato individual de utilização" (BENVENISTE, 1989, p. 81)

Para abordar o fenômeno da fala que se escuta na canção, não pretendo me colocar no mesmo âmbito em que se situaria uma abordagem sociolinguista. A base, entretanto, é a mesma, ou seja, o principio de que a língua quando falada deixa de ser um sistema fechado e imutável. Este é um legado deixado por William Labov ao se contrapor à ideia de sistema formulada por Ferdinand de Saussure. Mas é também o de Emile Benveniste para quem a fala em sua dimensão enunciativa, não se encontra fora, mas dentro do sistema linguístico. Isto equivale a observar a língua tendo como seu lugar de emergência a enunciação como ato de fala. Esta, por sua vez, configura um ato individual cuja primazia do gesto assenta-se na realização vocal (BENVENISTE, 1989, p. 83).

Ao focalizar a variedade da fala como enunciação, reporto-me teoricamente ao que faz existir a língua, isto é, a diferença inerente ao 
seu modo de ser como sistema. É que ouvindo um rastro vocal da fala cotidiana que vem pelas canções, vejo aí o caminho aberto para outra análise. Trago a direção de um trabalho analítico a ser procedido sobre a emissão da voz em letra e melodia expondo a fala acontecendo e dando lugar a um modo de ser e existir da língua. Isto deve ser considerado em certo tempo e espaço de exercício linguístico, isto é, o modo comunitário de articular a língua em atos cotidianos de fala.

O caso aqui é de tomar a variação linguística como acontecimento da língua na fala. Porém, em vez de descrever tais manifestações em seu estatuto teórico de variações históricas e regionais, tomo a direção de tomar os fenômenos de variantes dentro de uma mesma língua como acontecimento socio enunciativo. Emprego a expressão "sócio enunciativo" para significar o a mais da fala como variedade linguística, ou seja, a representatividade ampliada de múltiplas falas emitidas em uma e cada voz em coro numa canção. Isto significa que em cada modo de fala testemunhado na voz da canção há uma comunidade falante autoafirmada. Em consequência tem-se uma língua marcando na canção, a contra-apelo, a memória de como existiu em certo tempo e lugar. Cabe aqui lembrar a dimensão pragmática e performativa com Gilles Deleuze define a variante linguística, recusando a invariante como seu oposto: "A pragmática deve recusar a ideia de um invariante que poderia se abster das transformações, mesmo o invariante de uma 'gramaticalidade' dominante, pois a linguagem é caso de política antes de ser caso de linguística” (DELEUZE; GUATTARI, 1997, p. 97).

Em outras palavras minha questão não é a variedade linguística, mas sim o modo diferencial de a língua existir que se pode rastrear no legado cultural da canção popular. Há aí uma dimensão política que deve sempre permear minhas considerações neste artigo, a dizer, que alteração linguística verificada num mesmo idioma falado em um mesmo país acontece não para se por com maior ou menor prestigio, sim para autoafirmação perante outros modos de falar. Em outros termos, no limite originário e contingente da enunciação, a fala, na instância literária ou do cancioneiro em que aparece, mostra-se capaz de poesia, de música, enfim de criação modos de vida. A fala que se escuta nas canções é o espelho de certo modo de existência da língua como acontecimento enunciativo vocal. Por isto devo me ater à enunciação realizada na palavra cantada. 
A ideia é considerar como modos de dizer em variedades historicamente localizáveis resistem e insistem sob maneiras diversas de articulação e pronunciação na voz. O pressuposto é de que não há dissociação entre a estruturação linguística, em sua letra e melodia, e a voz que a torna possível em enunciação.

Pode-se assim estabelecer um corpus de canções que atravessam a história e vem a ser emitidas por diferentes vozes de cantores em diferentes tempos. Mas agora, para esta nova etapa do projeto, já não se trata da voz do interprete e sim da voz que vem da língua materializada nas canções. Em outros termos, trata-se de sintonizar a escuta analítica nesta outra voz a qual a voz deste ou daquele cantor se submete fazendo vocalmente aparecer uma maneira de a língua existir em sua variância ligada uma certa situação socio-enunciativa.

Nesta perspectiva, partindo do que tenho acumulado em trabalhos em que abordo a voz como enunciação, notadamente no ato de cantar, pretendo trabalhar sobre o que se arquiva na voz enquanto modos de existência da língua na fronteira entre a fala e o canto. O escopo da pesquisa recai agora sobre a fala ou evento de enunciação que é pressuposto do modo de dizer que se faz presente nas canções. Aludo aqui às contribuições de Luis Tatit, a que deve voltar mais adiante.

\section{Arquivo da língua falada nas canções}

Passo agora a esboçar a análise de alguns dos exemplos de obra cancioneiro como demonstração do que pode ser um levantamento dos modos de existir da língua na voz arquivada em memória das canções. O interesse é propor elementos que registram a memória da língua não em sua sistematicidade fechada, mas enquanto enunciação vocalmente realizada em cenas do cotidiano. O caso é de trabalhar como memória da língua aquilo que ficou efetivamente atestado nas séries múltiplas de enunciação na e por uma língua, visando esta como efeito de gestos vocais constituindo sujeitos em interações que inventam comunitariamente um cotidiano.

O cancioneiro popular brasileiro tem como ponto de origem certos modos de falar o português que ganha proeminência no vozeado das canções. Luiz Tatit afirma que o próprio da canção, em sua estrutura de letra, harmonia e melodia, é implicar a fala que existe por trás da melodia. Toda melodia, para ser canção, é preciso poder ser falada, ou 
seja, ser emitida na forma da linguagem cotidiana. Nela deve se escutar o ritmo da entonação do "sobe e desce" característico da fala.

A fala está presente, portanto, no mesmo campo sonoro em que atuam a gramática do ritmo fundando os gêneros e a gramática da frequência fundando a tonalidade. A presença da fala é a introdução do timbre vocal como revelador de um estilo ou de um gesto personalista no interior da canção. Se o ouvinte chegar a depreender o gesto entoativo da fala no "fundo" da melodia produzida pela voz, terá uma compreensão muito maior daquilo que sente quando ouve um canto (TATIT, 2003, p. 9).

Penso no ritmo da fala do pescador que o compositor Dorival Caymmi foi o único a registrar. Destaco especialmente a dimensão de acontecimento assentado em práticas culturais situadas no contexto do trabalho. Já nos primeiros acordes emitidos pela voz do compositor na canção $O$ vento:

Vamos chamar o vento

Vamos chamar o vento

Vamos chamar o vento

Vamos chamar o vento

Vento que dá na vela

Vela que leva o barco

Barco que leva a gente

Gente que leva o peixe

Peixe que dá dinheiro, Curimã

Curimã ê, Curimã lambaio

Curimã ê, Curimã lambaio

Curimã

Curimã ê, Curimã lambaio

Curimã ê, Curimã lambaio

Curimã

Quem escuta atentamente é levado à ambiência da atividade pesqueira em certo tempo e lugar. Isto que se observaria como transposição sensitiva de um plano físico para uma atmosfera de 
motivações psicológicas (Paulo Silva, 2016), anoto como a percepção acústica de um exercício ordinário de linguagem. Sim a repetição, a modo de um mantra, remete ao balançar dos barcos buscando o peixe que vem ao chamado do vento.

Por ouro lado, com Émile Benveniste (1989b, p. 285), é possível atentar, na prática cotidiana da pescaria, que o vaivém da palavra sugere uma troca, portanto uma "coisa" que trocaríamos". Condado, ainda assim, podemos separar a função instrumental da linguagem do objeto ou da ação a que se refere. A partir da clivagem entre linguagem e referente, e observamos o próprio da linguagem que a fala manifesta. $\mathrm{Na}$ voz do cantor o entoar dramatiza a fala que acontece indicando a conversa entre pescadores em uma lida que pede trabalho de intensa concentração. Isso é o que leva ao registro de um modo de falar o português social e subjetivamente situado nas canções praieiras de Dorival Caymmi. Trata-se do índice de onde vem a fala neste gênero de canção. Deixo, nesta consideração, os elementos procedimentais que deve se estender em trabalhos vindouros.

Percorro, nesta mesma perspectiva, a produção cancioneiro de compositores como, Noel Rosa, Paulo Cesar Pinheiro e Lupicínio Rodrigues. Em Noel Rosa a fala ordinária é também tema de suas letras. Noel usa a junção letra e melodia para comentar a fala, inclusive em sua distância crítica em relação aos registros enunciativos de norma culta. Com isso se serve do falar cotidiano de seu espaço e de seu tempo como fonte de inspiração. Um de seus sambas. Não tem tradução, composição de 1933, é um dos exemplares mais evidentes da referência à fala do morro e do malandro, num gesto de autoafirmação da fala do ambiente urbano carioca:

A gíria que o nosso morro criou

Bem cedo a cidade aceitou e usou

Mais tarde o malandro deixou de sambar, dando pinote

E só querendo dançar o fox-trote

Essa gente hoje em dia que tem a mania da exibição

Não entende que o samba não tem tradução no idioma francês 
Tudo aquilo que o malandro pronuncia

Com voz macia é brasileiro, já passou de português

Amor lá no morro é amor pra chuchu

As rimas do samba não são I love you

E esse negócio de alô, alô boy e alô Johnny

Só pode ser conversa de telefone.

Destaca-se nos versos deste samba duas estratégias de enunciação tematizando o modo de falar do sambista carioca. Uma comenta afirmativamente o fala a que se refere: "A gíria que o nosso morro criou/Bem cedo a cidade aceitou e usou”. Outra estratégia enunciativa, no corpo da mesma canção, refere literalmente a diferença da fala do outro: dando pinotel Amor lá no morro é amor pra chuchu.

Entretanto, quero atentar não para as palavras. Da gíria, sim para o ritmo e prosódia da variante de uma língua que serve a Noel Rosa em suas composições. A maciez que marca o andamento de "não tem tradução" é o reflexo da leveza e volteio da fala do malandro. É nisto que "as rimas do samba não são I love you”, e "esse negócio de alô, alô boy e alô Johnny só pode ser conversa de telefone”. Afinal o jeito cadente de o malandro falar não cabe em um português, afetado pela língua inglesa, à época em que Noel Rosa compôs este samba,

Comentando ou citando, é como se Noel Rosa fizesse a fala macia do morro aparecer diretamente, na sonoridade da letra e da melodia, pela própria voz do falante local que deve se amalgamar à do cantor. Desta maneira, o compositor se serve da fala do outro para trazer para sua linguagem cancioneira a musicalidade própria dessa fala outra. Dizer que tudo aquilo que o malandro pronuncia com voz macia é brasileiro, já passou de português descreve o furo nas fronteiras do prestigio que separam o culto do popular.

Tem-se assim uma descrição do ato enunciativo de afirmar e alocar a diferença da fala lá onde não tem lugar nos contornos excludentes do arquivamento de modos de existência da língua. Mais do que centralizaria as informações acerca das características da comunidade falante trazida para a linguagem da canção popular é preciso ressaltar o andamento das palavras que estabelece o regime de enunciação vocal descrevendo um modo de existir da língua na fala. 
Paulo Cesar Pinheiro, situado bem depois, na história da canção popular brasileira, mostra que por trás de suas canções há a voz de uma comunidade de fala vindo de diferentes regiões do exercício da língua portuguesa no Brasil. No trabalho composicional de Paulo Cesar Pinheiro pode-se atestar as diferentes possibilidades melódicas do falar o idioma português de que se serve o compositor na criação de suas canções.

Escolho para análise do efeito de presença da fala ordinária na letra e melodia uma de suas composições feitas em parceria com Baden Power. Foi uma de suas obras mais difundidas nas emissoras de rádio nos anos de 1970, na voz de Elis Regina: Vou deitar e rolar (Quaquaraquaquá).

Não venha querer se consolar

Que agora não dá mais pé

Nem nunca mais vai dar

Também, quem mandou se levantar?

Quem levantou pra sair

Perde o lugar

E agora, cadê teu novo amor?

Cadê, que ele nunca funcionou?

Cadê, que ele nada resolveu?

Quaquaraquaquá, quem riu?

Quaquaraquaquá, fui eu

Quaquaraquaquá, quem riu?

Quaquaraquaquá, fui eu

Ainda sou mais eu

Mas que malandro sou eu

Pra ficar dando colher de chá

Se eu não tiver de colher?

Vou deitar e rolar

Este é um samba que usa a gargalhada como modo de enunciar o sarcasmo numa fala vingativa, que vem do jeito suburbano de dizer desilusões amorosas. A versificação que Paulo Cesar Pinheiro imprime para esta letra que se conjuga com a melodia proposta por Baden Powell 
leva diretamente à fala enquanto entretece uma conversa. A cadência é feita de pausas e tessituras interpostas, isto e, cortes pontuais de silêncios breves e sobe e desce intermitentes no andamento rítmico.

É possível descrever aqui a fala espontânea do subúrbio carioca nos instantes em que se profere um aviso com efeito de desforra. Em dois tempos, o falante emite um enunciado com o mesmo valor de aviso. Isto o ouvinte do fonograma reconhece pela cadente entoação dos versos. Ao enunciar, o tom é, por um lado, assertivo em "não venha querer se consolar/ agora não mais pé; e, por outro, enfático em "nem nunca mais vai dar".

O que viria, no plano escrito, sob o apoio da pontuação, no plano oral vem pelo que a voz emite na tonalidade informando, mediante a maneira de falar, sobre a atitude de quem fala. Ao dizer: "porque vai ser fogo me aturar", a voz entoa mantendo-se na mesma tessitura até que, depois de repetir o tom enfático em "quem levantou pra sair/perde o lugar ", emite um volteio pela voz ao dizer em tom de cobrança: " $E$ agora, cadê teu novo amor?/Cadê, que ele nunca funcionou?/Cadê, que ele nada resolveu?" Este encadeamento segue no seu tom sincopado incidindo como prova a protocolar sarcasticamente a desforra até explodir na curva tonal mais alta irrompendo com a voz uma rasgada gargalhada, feita não de palavras, mas de uma repetição da mesma sílaba: Quaquaraquaquá, quem riu? / Quaquaraquaquá, fui eu.

Neste ponto dizemos que como os recursos prosódicos da língua falada são apropriados. Pelo compositor para dramatizar, na superfície textual da canção, uma cena de conversa. Mais do que o que se passa no diálogo sobre o estado dos protagonistas, o compositor faz ouvir o modo de falar afirmando uma variável linguística em precisa situação enunciativa. Neste sentido, diria, Gilles Deleuze (1997, p.30), o falante pode passar "constantemente de uma língua a outra". Na canção em análise, quero atentar para o modo como deve falar o amante em uma língua de sarcasmo. Esta é a precisa situação enunciativa em que o falante marca pela voz a passagem de uma língua para outro.

Há aqui uma colocação da vingança em ato na e pela maneira de falar, indiciando o falante em trânsito de uma variável linguística para outra. Tal como o fez Lupicínio Rodrigues, - ele jamais admitiu correções gramaticais em suas letras ${ }^{2}$ - em seu célebre samba Vingança:

Eu gostei tanto, tanto quando me contaram 
Que the encontraram chorando e bebendo na mesa de um bar

E que quando os amigos do peito por mim perguntaram

Um soluço cortou sua voz, não lhe deixou falar

$\mathrm{Ah}$, mas eu gostei tanto,

Tanto quando me contaram

Que tive mesmo que fazer esforço

Pra ninguém notar

A composição de Paulo Cesar Pinheiro e Baden Powell traz também a feição de uma conversa, de um acerto de contas entre amantes agravados que se pode dar na rua, na cozinha ou num bar de um subúrbio típico do Rio de Janeiro ou Porto Alegre. No entanto, o que uma canção difere em relação a outra não é o modo amargurado contra o bem-humorado de dizer a vingança, mas a exposição de duas falas marcando respectivamente dois modos de a língua portuguesa existir em cada tempo e lugar.

Certamente não é o caso de negar o que se constituir. No domínio da Sociolinguística como conceito de variações relativamente à mesma língua falada em diferentes regiões. E. diferentes camadas sociais de um território nacional. O que me interessa é deslocar a perspectiva da diferença do português falado com respeito ao sistema que o define para o acontecimento da língua em cada caso. Este ponto de vista faz ver a língua não já dada em seu fechamento sistemático, mas existindo enquanto é falada.

Daí vem o olhar sobre a língua falada. em sua propriedade singular de produzir a si mesma enquanto ao mesmo tempo produz a comunidade que fala. Neste sentido a letra do samba do Arnesto, de Adoniran Barbosa, não é apenas o registro de variação linguística remetendo a níveis de fala - culta ou popular, mas sobretudo os índices da existência. Da língua portuguesa. No ambiente. Urbano da cidade de São Paulo nos anos de 1960.

O Arnesto nos convidou pra um samba, ele mora no Brás

Nós fumos não encontremos ninguém

Nós voltermos com uma baita de uma reiva 
Da outra vez nós num vai mais

Nós não semos tatu!

No outro dia encontremo com o Arnesto

Que pediu desculpas mais nós não aceitemos

Isso não se faz, Arnesto, nós não se importa

Mas você devia ter ponhado um recado na porta Um recado assim ói: "Ói, turma, num deu pra esperá

Aduvido que isso, num faz mar, num tem importância,

Assinado em cruz porque não sei escrever

Do mesmo modo que constatamos a existência de uma maneira de falar o português por descendentes de imigrantes italianos, percebemos também, acusticamente, que a fala transmitida nesta canção reconfigura certo processo histórico de enunciação. Aludo ao jeito com que o compositor se apropria de formas lexicais presentes na fala de uma região urbana de falantes vindo da zona rural colonizada por italianos. A letra e a melodia prosódicamente articulando as palavras verificáveis no jargão popular ao ritmo da fala no que vai dar no estilo do samba em São Paulo. Desta forma, ressalta-se mais do que o suposto erro na grafia e pronúncia das palavras o andamento da fala que se transfere para este samba paulistano.

Note-se a quebra ritmicamente calculada quando dentro da melodia vem o verso "Nós não semos tatu!". Sem rejeitar certo linguajar existente na fala de uma camada popular paulistana, Adoniran Barbosa segue bem as regras de composição de um samba de breque, colocando pausa no ponto acentual e sincopado da cadeia enunciada, antes de prosseguir com a intervenção de novo dado da narrativa: "No outro dia encontremo com o Arnesto/Que pediu desculpas mais nós não aceitemos..."

O caso não é do uso de uma mesma língua, mas da afirmação de um entre outros usos, passando, sem deixar de ser outro, por dentro do sistema considerado padrão. Nisto é que aqui advogo pelo modo variável e diferencial de uma língua existir. Tal diferença e variável nunca se situa fora da língua existente. Vejamos como o próprio Deleuze (op. Cit., p. 30) defende este ponto de vista. 
Objetar-se-á que essas variações são extrínsecas, e que o que ele usa não deixa de ser a mesma língua. Mas afirmá-lo é prejulgar o que está em questão. Pois, por um lado, não é certo que seja a mesma fonologia, nem a mesma sintaxe, a mesma semântica. Por outro, toda questão é a de saber se a língua considerada a mesma se define por invariantes ou, ao contrário, pela linha de variação contínua que a perpassa. Alguns lingüistas sugeriram que a mudança lingüística se faz menos por ruptura de um sistema do que por modificação gradual de frequiência, por coexistência e continuidade de usos diferentes.

Isto é o que confere forma de existência a uma língua assentada no limiar de um referencial de identidade nacional. É quando a história do português falado no Brasil quebra fronteiras de nacionalidade para inscrever-se em seu modo próprio de existir sendo falado.

\section{Concluindo}

Por certo, podemos observar no entoar da canção o registro de um modo de falar próprio de uma comunidade linguística. O que mostra que se trata de uma maneira de existir da língua que se difunde em sua estrutura oral pela voz na canção. Com isso, deixo de lado o emprego das palavras como ferramentas, nem mesmo da gíria como estratégia de mimetizar o falante. Quero tomar a canção como modo de existência da língua que se manifesta na fala, problematizando modelos de descrição linguística orientando para a busca do traço ontológico a sustentar uma língua.

Em verdade, o que serve de ferramenta disponível aos ouvidos do compositor e a língua transmitida em fluidas modalidades de existência expondo diferença a cada ato de enunciação. É nesse sentido a fala que se escuta sendo transferida para a superfície textual da canção contém uma musicalidade oferecida à escuta do compositor para tecer sua enunciação. Deste modo, a fala nas canções não remete termo a termo a um modo prévio de falar, nem mesmo enquanto variáveis passiveis de fazer corpo num previsível e necessário sistema de regras gramaticais. A remissão é inversa, pois, conforme diria Benveniste 
qualquer modalidade linguística para que se faça existir, é preciso haver homens falando." Não atingimos jamais o homem reduzido a si mesmo e procurando conceber a existência do outro. É um homem falando que encontramos no mundo, um homem falando com outro homem. e a linguagem ". Portanto o modo de existir da língua corresponde ao modo de existir do homem ou do sujeito na fala (BENVENISTE, 1997, p. 285).

O que tento, com a preposição analítica que aqui desenvolvo é mostrar a canção, para além do que a constitui como linguagem musical, realiza a transmissão da fala sinalizando modos outros de existência da língua em circunstâncias precisas de enunciação. É possível adotar assim uma atitude analítica de escuta em que mais que maneiras de comunicar ou informar conteúdos culturais, a fala transmutada em canção traça uma cartografia de processos de inscrição de falares dentro de uma mesma língua. Neste quadro, o que a fala, como modo de fazer a língua, produz é a autoafirmação do lugar de enunciação, quer seja este lugar de natureza comunitária ou individualÉ dizer que nas canções de Dorival Caymmi ou Adoniran Barbosa, por exemplo, não é o baiano que se escuta, mas a língua existindo como condição de uma auto afirmação.

Não se trata de uma fala se sobrepondo a outra, mas do estatuto de autoafirmação das respectivas comunidades de fala que se fazem ouvir pela voz da canção. Não existe a língua, mas maneiras irredutíveis de se apropriar dela e fazer dela uma fala. Se levarmos em conta o extenso alcance da cultura popular feita em forma de música, pode-se situar a memória da língua produzindo diferença. Isto deve ser considerado no quadro em que está posto o estatuto linguístico de certos falares operados pela divisão norma culta/norma popular. Entretanto a canção popular reverte as regras linguísticas desse jogo. Em vez de língua de prestígio da classe dominada, a canção faz escutar a afirmação de um modo de falar que não está presente a não ser na comunidade de referência, à qual está a voz que canta uma canção.

Nesta história, o que importa não é a detecção de falares, situados na língua portuguesa, em que um se sobrepõe a outro. O que interessa, investigar é a forma vocal da relação com que cada modo de enunciação se realiza ao mesmo tempo em que se autoafirma na musicalidade própria a seu falar. É para a autoafirmação e não para a submissão que a língua falada na canção aponta. Proponho, neste sentido, um modo de 
ouvir a voz como agenciamento político de comunidades de fala. A fala de que se apropria o cancionista define-se não através de um pedido de concessão de outros falares dominantes na língua, mas por uma estratégia que pela voz a comunidade faz afirmação de si.

Assim se pode abordar como variante linguística na canção traz uma voz inserida numa comunidade de fala, afirmando uma maneira entre outras de a língua existir. Não se trata, portanto, da diferença que marca o prestígio de uma variável linguística, mas da condição de existência da comunidade que, em séries históricas de enunciação, agencia e inscreve um modo de falar na história da língua.

Trata-se de pensar uma outra dimensão da variedade linguística que não se encontra nem em forma sintática e na forma das palavras empregadas, mas no modo como a voz dá a ouvir o mesmo arranjo linguístico soando em outra esteira temporal da língua. Por certo, vem aí um efeito de sobreposição, fazendo ressoar sobre uma voz emitida, em certo tempo preciso, outra que vem de outro lugar. Assim teríamos a mesma língua, mas tornada em uma fala que marcando diferença na apropriação que dela faz o cancionista. Na canção, vem uma voz falando a língua em outra sonoridade.

A ideia é considerar como modos de dizer em variedades histórica e socialmente localizáveis expõem maneiras diversas de existência da língua falada na voz cantada. Deste modo, é preciso admitir que não há dissociação entre a estruturação linguística, em sua letra e melodia, e a voz que a torna possível em enunciação. Precisamente ressalto modos de falar que não seriam apenas variedades secundárias de uma mesma língua, mas maneiras de fazer escutar, na linguagem ordinária, traços de performances linguísticas que não viriam à tona a não ser na e pela forma da letra sonorizada dentro da melodia. Aí que se pode ver a canção dando a ver modos de dizer na língua que do da fala migra para o canto dando lugar variedades outras só emergentes porque vindo desta ou daquela canção.

É num conjunto de exemplares de composições populares que se pode basear para afirmar que o linguajar percebido em música faz existir singulares modos de falar. Daí é possível atentar para escuta de uma outra língua falada a partir da qual o compositor tece sua composição e remete o ouvinte à ambiência linguística que só pode se dar ouvir na canção em que aparece. 


\section{Referências bibliográficas}

BENVENISTE, E. “O aparelho formal da enunciação". In: Problemas de Linguística Geral II. Campinas: Pontes, [1970] 1989.

BENVENISTE, E. "Da subjetividade na linguagem". In Problemas de Linguística Geral, I. Campinas: Pontes, [1958] 2005.

DELEUZE, G., "20 de novembro de 1923 - Postulados da linguística". Tradução de Ana Lúcia de Oliveira e Lúcia Cláudia Leão. In DELEUZE; G., GUATTARI, F. Mil platôs - capitalismo e esquizofrenia; tradução de Ana Lúcia de Oliveira e Lúcia Cláudia Leão. - Rio de Janeiro: Ed. 34, 1995, p. 11-50.

PRETTI, D. "Mas como devem falar as personagens literárias", In Revista da Anpoll, no. 3, 1997.

\section{Notas}

* Doutor em Linguística pela Universidade Estadual de Campinas (UNICAMP), é docente da Universidade Federal de Santa Catarina (UFSC).

${ }^{1}$ Entrevista ao escritor e jornalista Arnaldo Saraiva, em 24 de novembro de 1966.In http://www.revistabula.com/383-a-ultima-entrevista-de-guimaraes-rosa/

${ }^{2}$ Sem dominar a linguagem formal da música e tocar instrumentos, tem apenas a voz para compor suas canções. Estas, afirma Lupicínio, fundam-se em experiências vividas por ele próprio ou por seus amigos, sempre ligadas à traição, ao desencanto, à paixão, aos dramas do amor. In LUPICÍNIO Rodrigues. In: ENCICLOPÉDIA Itaú Cultural de Arte e Cultura Brasileiras. São Paulo: Itaú Cultural, 2021.

Disponível em: <http://enciclopedia.itaucultural.org.br/pessoa6600/lupiciniorodrigues>. Acesso em: 23 de Jun. 2021. Verbete da Enciclopédia. ISBN: 978-85-7979-060-7. 